\title{
FROM NATURAL BRANCHINGS TO TECHNICAL JOINTS: BRANCHED PLANT STEMS AS INSPIRATION FOR BIOMIMETIC FIBRE-REINFORCED COMPOSITES
}

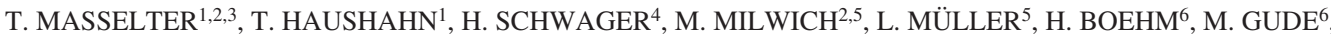 \\ A. GRUHL ${ }^{6}$, W. HUFENBACH ${ }^{6}$, C. NEINHUIS ${ }^{3,4} \&$ T. SPECK ${ }^{1,2,3}$ \\ ${ }^{1}$ Plant Biomechanics Group Freiburg, Botanic Garden, Faculty of Biology, University of Freiburg, Germany. \\ ${ }^{2}$ Competence Network Biomimetics, Baden-Württemberg, Germany. \\ ${ }^{3}$ Bionics Competence Network (BIOKON e.V.), Germany. \\ ${ }^{4}$ Botanic Garden, TU Dresden, Germany. \\ ${ }^{5}$ Institute for Textile Technology and Process Engineering Denkendorf, Germany. \\ ${ }^{6}$ Institute of Lightweight Engineering and Polymer Technology (ILK) TU Dresden, Germany.
}

\begin{abstract}
The manufacturing of nodal elements and/or ramifications with an optimised force flow is one of the major challenges in many areas of fibre-reinforced composite technology. The examples include hubs of wind-power plants, branching points of framework constructions in building industry, aerospace, ramified vein prostheses in medical technology or the connecting nodes of axel carriers. Addressing this problem requires the adaptation of innovative manufacturing techniques and the implementation of novel mechanically optimised fibre-reinforced structures. Consequently, the potential of hierarchically structured plant ramifications as concept generators for innovative, biomimetic branched fibre-reinforced composites was assessed by morphological and biomechanical analyses. Promising biological models were found in monocotyledons with anomalous secondary growth, i.e. Dracaena and Freycinetia, as well as in columnar cacti such as Oreocereus and Corryocactus. These plants possess ramifications with a pronounced fibre matrix structure and a special hierarchical stem organization, which markedly differs from those of other woody plants by consisting of isolated fibres and/or wood strands running in a partially lignified parenchymatous matrix. The angles of the Y-and T-shaped ramifications in plants resemble those of the branched technical structures. Our investigations confirm that the ramifications possess mechanical properties promising for technical applications, such as a benign fracture behaviour, a good oscillation damping caused by high energy dissipation and a high potential for lightweight construction. The results demonstrate the high potential for a successful technical transfer and led to the development of concepts for producing demonstrators in lab-bench and pilot plant scale that already incorporate 'solutions inspired by nature'.
\end{abstract}

Keywords: Branched fibre-reinforced composites, columnar cacti, lightweight, monocotyledons, Y- and T-shaped ramifications.

\section{INTRODUCTION}

The production of an ever increasing number and diversity of fibre-reinforced composites is driven by the high demand for lightweight materials with good damping, other beneficial mechanical properties and high standards for excellent performance in structures that are subjected to extreme tension, torsion and bending forces and moments. In many technical applications, these loadings are highly dynamic and may occur in many millions of load-unload cycles. These extremely complex and numerous combinations of stresses and strains that act on a structure can ultimately lead to material fatigue and cracks and thereby become critical for the structural integrity of the component (Fig. 1) [1, 2].

This is especially the case for mechanical parts that are subject to vibration and impact loads in fast-moving objects such as cars, planes or windmills. The failure of these structures often have catastrophic consequences and can lead to the collapse of the entire structure, e.g. the demolition of a windmill caused by the delamination of the rotor blades (www.forcechange.com) [3]. As 


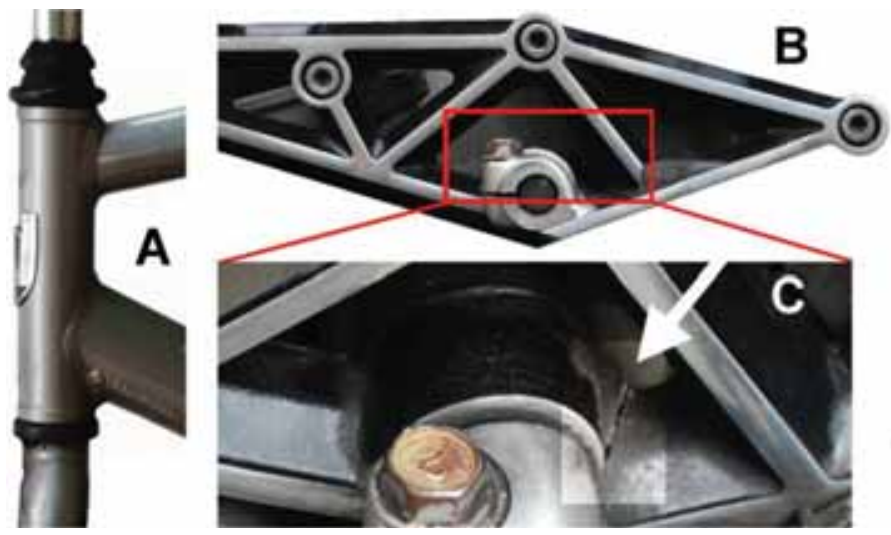

Figure 1: The technical challenges: nodal structures in motorbike-engineering and bicycleengineering. (A) The headset of a bicycle. (B and C) A subframe of a motorbike with fatigue crack (arrow).

fibre-reinforced composites hold the potential to meet these high performance standards, the production of such structures is often very difficult and complicated by the complex shape of many parts, especially branched elements. The combination of two approaches, i.e. the development of innovative production techniques combined with a biomimetic optimisation of the inner and outer structures of the fibre-reinforced composites, leads to novel bio-inspired structures with enhanced mechanical properties that are able to overcome the restrictions of classic engineering techniques for optimisation. The potential of nature as a role model for designing fibre-reinforced components is very high as (i) it combines different substructures into a superordinate structure, thus enhancing the mechanical characteristics, a principle that is common in nature, and (ii) the laminated configuration of technical products, e.g. a carbon-fibre-reinforced epoxy resin and some plant stems, e.g. the layered structures of a bamboo shoot are highly comparable $[4,5]$. The general potential of biomimetic approaches will be described for the specific example of branched technical fibre-reinforced composites.

The methodological approach for developing 'branched' composite structures can be described as a 'Top-Down process' as defined by the Plant Biomechanics Group (PBG) Freiburg (Fig. 2) [4, 6].

\section{MATERIALS AND METHODS}

\subsection{The biomimetic approach}

An R\&D project in biomimetics may be initiated by a specific technical challenge posed by an engineer of a company (technology pull, 'Top-Down process') (Fig. 2). The solution is often not limited to the constraint of one particular application, but rather can be implemented in a large number of products and may even generate new technical applications. The search for adequate concept generators in nature is the following step (i). This screening covers a broad spectrum of biological organisms in order to find the concept generators with the highest potential of 'solving' the technical problem. After the completion of the screening procedure, appropriate principles based on the structures and functions of one or more concept generators are identified (ii). To analyse quantitatively 




Figure 2: The Top-Down process (technology pull) for developing biomimetically optimised branched fibre-reinforced structures.

the form-structure-function relationships of the model plants, an array of methods, including biomechanical tests as well as different light- and electro-optical analyses (see below), are used. The abstraction process is the next step (iii). This part of the project is highly important for the success of the whole project. The underlying principles that were found in the biological organisms are detached from these and translated to technical materials and structures. Simulations of the structures can help to shed light on the complex form-structure-function relationships in the plants and thereby can aid the abstraction process (iv). This knowledge transfer from the biologists to the engineers forms the basis for assessing the possibilities for a technical implementation and makes it possible to carry out technical feasibility tests (v). In later steps, the natural structures are modelled and demonstrators are manufactured on the lab-bench scale and pilot plant scale prior to prototyping (vi). The biomimetically optimised structures are then finally introduced onto the market, accompanied by flanking measures from the industrial partner. This Top-Down process is in accordance with the newly defined guidelines 6220 [7] and 6223 [8] published by the VDI (Association of German Engineers/Verein Deutscher Ingenieure).

\subsection{The structural and mechanical analyses of the arborescent monocots and columnar cacti}

In the PBG of the University Freiburg, serial thin and semi-thin sections were made for analysing the morphology and anatomy of the branch-stem attachment regions of Dracaena and Freycinetia, two of the role models for branched biomimetic fibre-reinforced composites [9-14].

The numerical structural analyses of stem-branches by finite-element analysis for the investigation of geometric influences to the branch stiffness are performed at the Institute of Lightweight Engineering and Polymer Technology (ILK) of the TU Dresden using 2D-models with shell elements, which have been generated by a fringe pattern projection system (Fig. 3).

For analysing the external and internal organisations of the branching regions in monocotyledons and columnar cacti in detail, scanning electron microscopy and microtomography were employed (Fig. 4). These methods allow transferring the morphology of the concept generators, e.g. Corryocactus brachypetalus (Fig. 4A) into a 3D model of the organisation of the wood lamella (Fig. 4B) 


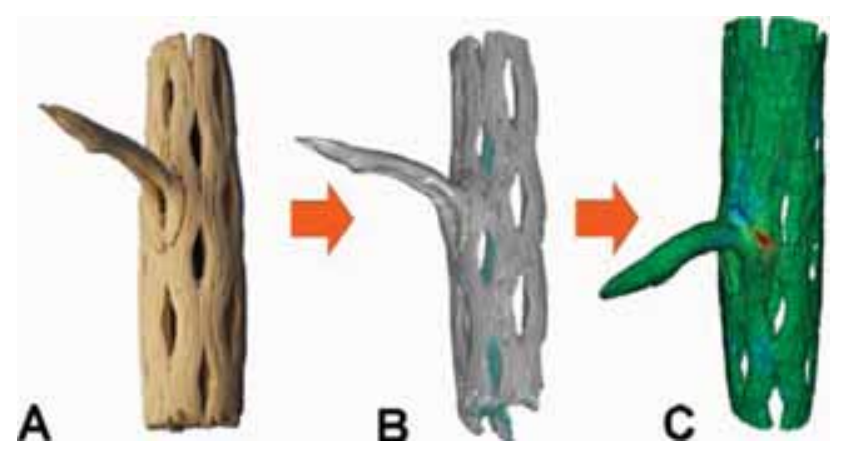

Figure 3: Oreocereus fossulatus. (A) Anatomical analysis; (B) CAD modelling (fringe pattern projection system); and (C) FE simulation.

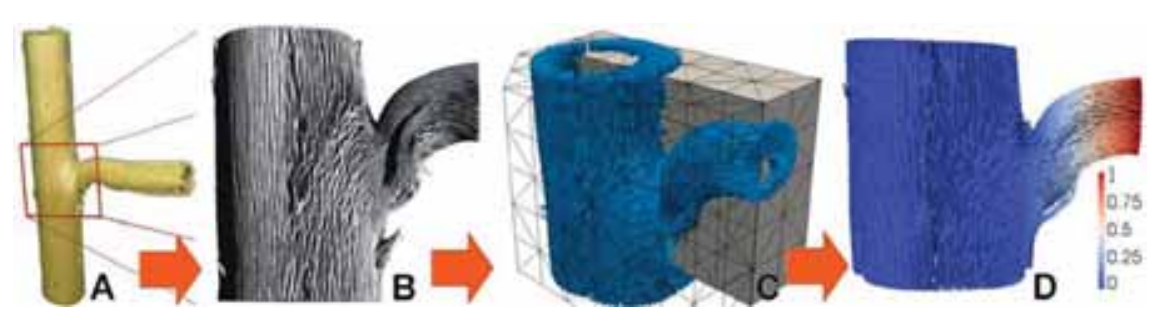

Figure 4: The stem-branch attachment regions of Corryocactus brachypetalus. (A) The external view of the wood cylinder; (B) the 3D-model of a stem based on Micro-CT data; (C) the mesh of the FE model; and (D) the simulation for displacement.

that can be used as a basis for generating a finite-element model with 2 million volume elements for a structural analysis (Fig. 4C) [15]. Numerical simulations (Fig. 4D) [16] are used in order to investigate the influence of the inner structure of the plant stems on the deformation behaviour and to draw conclusions on the optimal fibre arrangement in technical composite structures. These arrangements can then be integrated at gussets of technical fibre-reinforced structures (see below). The required material properties, such as the directional-dependent Young's modulus, Poisson's ratio and shear modulus, for the simulation are determined in extensive loading tests on natural specimens at the Institute for Botany (BTU) of the TU Dresden taking the material's anisotropy into account (Fig. 5).

For this purpose, specimen cut out of the lignified vascular tissue were tested in monoaxial tensile tests with optical deformation analysis in different angles to the stem axis at the BTU as well as at the PBG (Fig. 5). The axially oriented strands were used to assess the Young's modulus in fibre direction and the axial-tangential and axial-radial Poisson's ratios (Fig. 5C). Owing to the small diameter of the vascular cylinder of the investigated species Corryocactus brachypetalus, ring-shaped specimen had to be used for measuring the Young's modulus perpendicular to the fibre direction (Fig. 5A). The shear modulus was calculated in a polar transformation of the Young's modulus of ring-shaped specimen cut in an angle of $30^{\circ}$ to the stem axis (Fig. 5B). For the missing material properties that are needed as input parameters for the finite-element analysis, appropriate assumptions were made. 


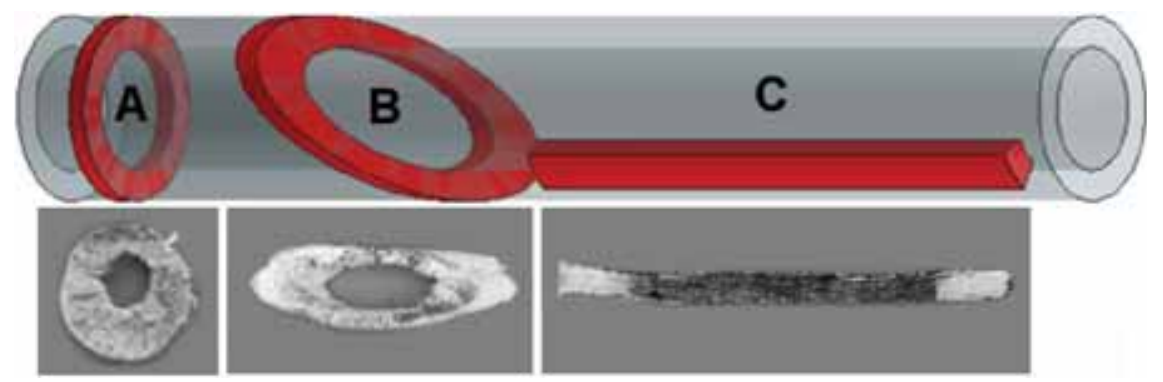

Figure 5: Material testing of lignified vascular tissue specimen of Corryocactus brachypetalus in different angles relative to the stem axis: (A) perpendicular to the stem axis; (B) in an angle of $30^{\circ}$; and (C) parallel to the stem axis.
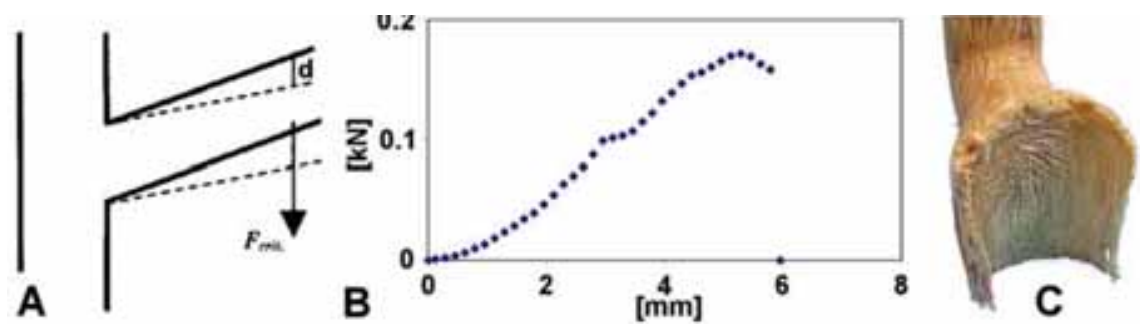

Figure 6: Breaking experiments. (A) A schematic drawing of the geometry of the stem-branch attachment. The solid line represents a lateral twig before bending, the dashed line represents a lateral twig shortly before fracture, $F_{\text {crit }}$ is the critical force necessary to break the twig and $d$ is the vertical displacement until fracture. (B) The exemplary forcedisplacement curve measured for Dracaena reflexa by the fracture mechanics test setup shown in (A). (C) Sickle-shaped fracture mode (see [9]).

Additionally, the biological concept generators were tested biomechanically at the PBG. These tests include breaking experiments in which a force is applied to a lateral twig until this twig breaks (Fig. 6), using similar methods as described in detail in [17]. This setup allows one to determine the force necessary to break the twig (Fig. 6A) and the fracture toughness as well as the force and displacement (Fig. 6B) at fracture and to characterise different fracture modes (Fig. 6C).

\section{BRANCHED FIBRE-REINFORCED COMPOSITES}

Monocotyledons such as Dracaena and Freycinetia as well as columnar cacti such as Oreocerus fossulatus (Fig. 3) and Corryocactus brachypetalus (Figs 4 and 5) show Y- and T-shaped branchings that in their angles resemble those of branched technical components. In these biological concept generators, isolated fibres and/or wood strands run in a partially lignified parenchymatous ground tissue matrix, so that they form per se natural fibre-reinforced composites (Figs 3, 4B, 7C and 8C). The plants are hierarchically arranged on at least five levels: (i) the form of the branching (Figs 7B and 8B), 

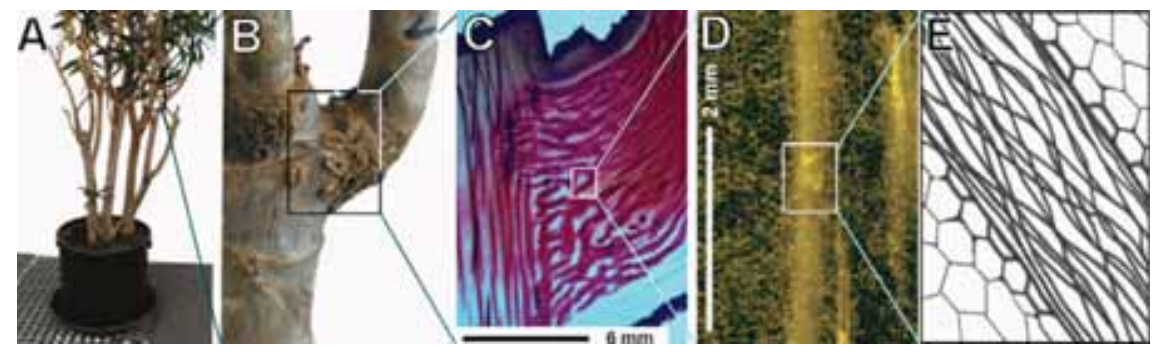

Figure 7: The hierarchical organisation of the natural concept generators (Dracaena sp., monocotyledons). (A and B) The form and diameter of the stem-branch attachment region, $(\mathrm{C})$ the arrangement of the fibre bundles and the course of the individual fibres, (D) the anatomy of the fibre bundles and (E) the schematic ultra structure of the fibres as well as the gradients between the fibre bundles/fibres and the matrix.
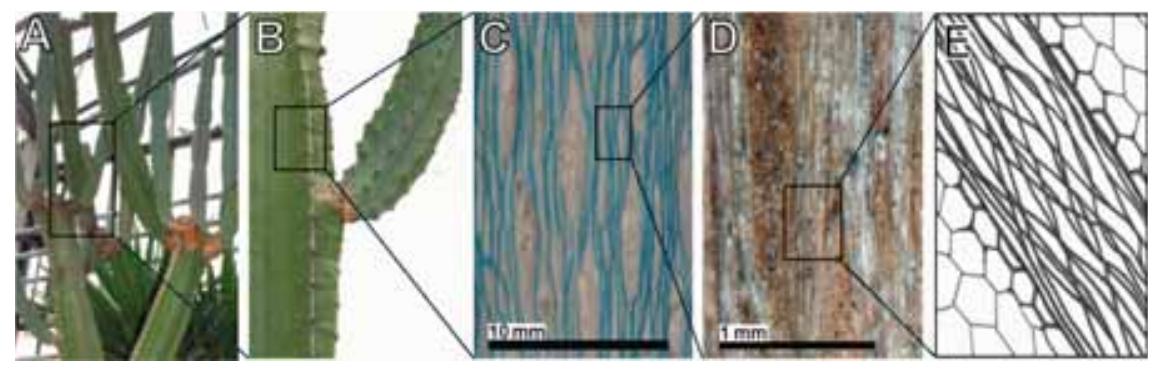

Figure 8: The hierarchical organisation of the natural concept generators (Cereus sp., columnar cacti). (A and B) The form and diameter of the stem-branch attachment region, (C) the arrangement of the fibre bundles and the course of the individual wood strands, (D) anatomy of the wood strands and (E) the schematic ultra structure of the strands as well as the gradients between the strands and the matrix.

(ii) the arrangement of the fibre bundles (Fig. 7C) or wood strands (Fig. 8C), the course of the individual fibre bundles (Fig. 7C) or the wood strands (Fig. 8C), (iii) the anatomy of the fibre bundles (Fig. 7D) or wood strands (Fig. 8D), (iv) the ultra structure of the fibres or wood strands as well as (v) the gradients between the fibre bundles/fibres/wood strands and the matrix (Figs 7E and 8E).

Although the axes of both monocots and cacti are optimised at these hierarchical levels, the morphology and hierarchical structuring of the stem-branch attachments differ in the two groups of plants, i.e. the angles, the course and the arrangement of the fibre bundles or wood strands in the matrix are highly different (compare Figs 7 and 8).

In Dracaena, a network of somewhat helically, but mostly paraxially, arranged fibrous bundles in large parts of both the stem and branch has developed in the course of evolution as an adaptation to complex loading conditions. Furthermore, this has led to a complex interwoven pattern in the regions where the branch is connected to the stem (Figs 7C and 9C). In simple terms, the stem and branch can be considered to be (i) non-hollow tubes that are interconnected by (ii) a complex pattern of fibres with a (iii) larger diameter at the interconnecting region. 

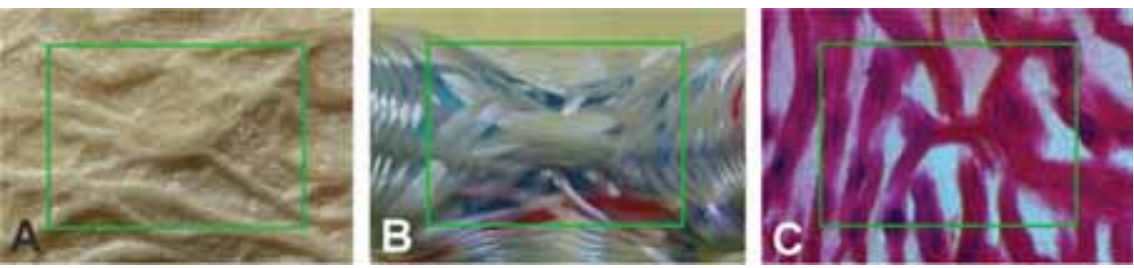

Figure 9: The natural and technical fibre-reinforced composites. (A) Convoluted woody strands at the stem-branch attachment region of Cereus sp., (B) enhanced gusset of the fibrereinforced composite produced at the ITV and (C) convoluted fibrous bundles in the stem-branch attachment region of Dracaena reflexa. Scale bars (width of green box): (A) $4 \mathrm{~mm}$, (B) $15 \mathrm{~mm}$ and (C) $3 \mathrm{~mm}$.

In a similar manner, the wood strands in the stems and branches of columnar cacti are also more or less paraxially arranged showing a net-like interconnection (Fig. 8C), but in contrast, they form a very different pattern at the stem-branch interconnection (Figs 4B and 9A). The stems and branches of columnar cacti can be reduced to (i) woody tubes filled by a non-lignified parenchymatous pith with an interconnection displaying a (ii) complex but differently arranged pattern of wood strands and (iii) often a smaller diameter at the interconnection (Figs 4A and 8B).

Different modes of fracture with distinct force-displacement curves were found as the first results for the fracture mechanics in the monocotyledons and cacti. One of these modes of fracture of Dracaena reflexa is sickle-shaped (Fig. 6C). This mode of fracture can be correlated with a forcedisplacement curve that shows a benign breaking behaviour, i.e. with a long plastic range.

The transfer of the branched biological role models into technical products requires the use of modern techniques and methods. The braiding technique is predestinated to transfer the optimised structures of the plants, above all the fibrous bundles, into technical products and manufacture tubular preforms $[18,19]$.

More specifically, the overbraiding technique or the 3D-rotary braiding technique is used to manufacture braids of elementary shapes, which can be used as reinforcement of lightweight structures [20-23].

Using these techniques, the Institute of Textile and Process Engineering (ITV) in Denkendorf has been able to manufacture Y-shaped branchings with enhanced gussets (Fig. 9B) that are very similar to the structures found in plants (Fig. 9A and C).

At the ILK, a variable braiding eye (Fig. 10A) allows for manufacturing technical branchings (Fig. 10D) with an enhanced hierarchical structuring following the arrangement in plants (see Figs 7-9 and [24]). With the variable braiding eye (Fig. 10A) the small parts of the braiding mandrel can be braided with a closed eye (Fig. 10B) where the distance between the deviation point of the fibres and mandrel is very small. With an open variable braiding eye (Fig. 10C), the branched structure can be moved through before the mandrel is rotated and another branch of the structure is braided. In addition to that, compared to braiding eyes with constant diameters the variable braiding eye enables a much more load-adapted fibre deposition on the braiding mandrel with regard to the expected states of stress under loading conditions.

The potential fields of implementation of the branched fibre-reinforced structures are similar to those of the 'technical plant stem', a fibrous composite structure developed by the PBG Freiburg and the Institute for Textile Technology and Process Engineering Denkendorf [25-27]. Additionally, the biomimetically optimised joints can connect tubular-shaped fibre-reinforced composites and shall be 


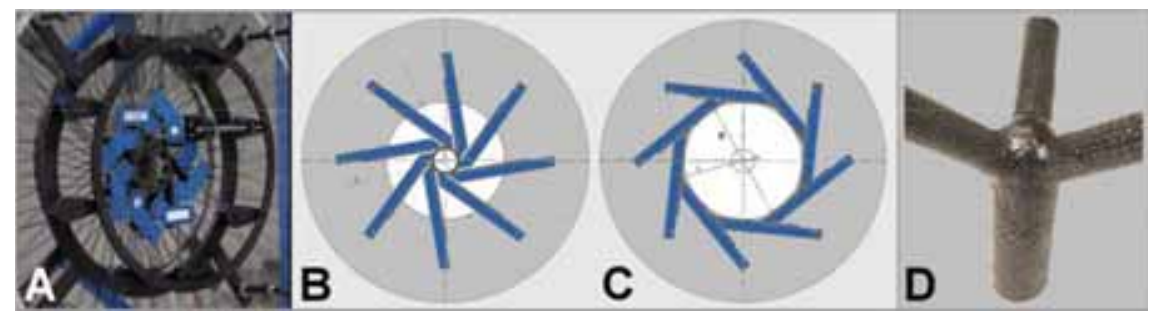

Figure 10: The variable braiding eye. (A) The variable braiding eye mounted in a radial braiding machine, $(\mathrm{B}$ and $\mathrm{C})$ the schematic drawing of a variable braiding eye in closed position (B) and open position (C) and (D) the multiple-branched braided composite demonstrator manufactured at the ILK.

able to bear high loads and moments following the example of the branched biological role models (Figs 3-9). It is important to design these joints in a way that the continuation of the fibres from the tubular structures through the joint and to the next tubular structure is guaranteed, similar to the stem-branch attachment structures in columnar cacti (Fig. 4B) and arborescent monocotyledons (Fig. 7C). The mechanical load capacity in the joint can be adjusted to be higher than the load capacity in the tubes, if this is of technical interest. This can be performed by adjusting the amount, the diameter and the arrangement pattern of the fibres in the joint and, following the example of the biological concept generators, by implementing these adjustments on several hierarchical levels. Our goal is also to reduce cracks that form through excessive notch stresses in the joints and thus to increase the lifespan and safety of components for vehicle engineering (Fig. 1), aerospace and many other areas of lightweight engineering.

\section{ACKNOWLEDGEMENTS}

The authors gratefully acknowledge the DFG for funding the study within the Priority Programme SPP 1420 'Biomimetic Materials Research: Functionality by Hierarchical Structuring of Materials'.

\section{REFERENCES}

[1] Masselter, T., Barthlott, W., Bauer, G. et al. Biomimetic products (Chapter 12). Biomimetics Nature Based Innovation, ed. Y. Bar-Cohen, CRC Press: Boca Raton, London and New York, pp. 377-429, 2012.

[2] Masselter, T. \& Speck, T., Biomimetic fibre-reinforced compound materials (Chapter 9). Advances in Biomimetics, ed. A. George, INTECH: Rijeka, pp. 185-210, 2011.

[3] Forcechange.com, available athttp://forcechange.com/1726/when-windmills-explode/,(accessed 08 February 2013, 15:34).

[4] Speck, T., Harder, D. \& Speck, O., Gradient materials and self-repair: learning technology from biology. VDI-Report, B4284, pp. 1-13, 2007.

[5] Ehrenstein, G.W., Faserverbund-Kunststoffe: Werkstoffe, Verarbeitung, Eigenschaften, Hanser Fachbuchverlag: Muenchen, 2006.

[6] Speck, T. \& Speck, O., Process sequences in biomimetic research. Design and Nature IV, ed. C.A. Brebbia, WIT Press: Southampton, pp. 3-11, 2008.

[7] VDI Guideline 6220 'Biomimetics - Conception and Strategy. Differences between bionic and convential products'. Beuth: Berlin, 2012. 
[8] VDI Guideline 6223 'Biomimetics - Materials, structures and components'. (Official draft) Beuth: Berlin, 2012.

[9] Masselter, T., Eckert, S. \& Speck, T., Functional morphology, biomechanics and biomimetic potential of stem-branch connections of Dracaena reflexa and Freycinetia insignis. Beilstein Journal of Nanotechnology, 2, pp. 173-185, 2011. doi: http://dx.doi.org/10.3762/bjnano.2.21

[10] Masselter, T. \& Speck, T., From stems to sticks - what can we learn for biomimetics from natural fibre-reinforced structures? Proceedings of the 6th Plant Biomechanics Conference, ed. B. Thibaut, ECOFOG: Cayenne, pp. 357-366, 2009.

[11] Haushahn, T., Fink, S., Masselter, T. \& Speck, T., General biomechanics and functional morphology of Dracaena marginata. Proceedings of the 7th Plant Biomechanics Conference, ed. M. Fournier, INRA: Clermont-Ferrand, pp. 203-206, 2012.

[12] Haushahn T., Schwager, H., Neinhuis, C., Speck T. \& Masselter T., Plant ramifications inspire branched lightweight composites. Bioinspired, Biomimetic and Nanobiomaterials, 1, pp. 77-81, 2012. doi: http://dx.doi.org/10.1680/bbn.11.00011

[13] Schwager, H., Masselter T., Speck T. \& Neinhuis, C., Functional morphology and biomechanics of branch-stem junctions in columnar cacti. Proceedings of the Royal Society B (accepted September 2013).

[14] Schwager, H. \& Neinhuis, C., Functional branching morphology of arborescent columnar cacti. Proceedings of the 7th Plant Biomechanics Conference, ed. M. Fournier, INRA: Clermont-Ferrand, p. 221, 2012.

[15] Cichy, F., Gude, M., Danczak, M., Hufenbach, W., Schwager, H. \& Neinhuis, C., Simulation of branched biological structures for bionic fibre-reinforced components. Kompozyty, 11, pp. 304-309, 2011.

[16] Wenzlaff, M., Numerical analysis of the fibrous structure of columnar cacti. Student thesis, TU Dresden, 2013.

[17] Beismann, H., Wilhelmi, H., Baillères, H., Spatz, H.-C., Bogenrieder, A. \& Speck, T., Brittleness of twig bases in the genus Salix: fracture mechanics and ecological relevance. Journal of Experimental Botany, 51, pp. 617-633, 2000. doi: http://dx.doi.org/10.1093/jexbot/51.344.617

[18] Müller, L., Gruhl, A., Böhm, H. et al., Biomimetisch optimierte verzweigte Faserverbundstrukturen mit hoher Tragfähigkeit. Melliand Textilberichte, 2, pp. 88-93, 2013.

[19] Lepper, M., Renner, O., Gruhl, A. \& Hufenbach, W., Die Flechttechnologie - Zukunftsträchtiges Verfahren für die Fertigung komplexer Faserverbund Hohlstrukturen. Lightweight Design, 2, pp. 44-48, 2013.

[20] Drechsler, K., Composites im Flugzeug- und Automobilbau. Conference proceedings of Denkendorfer Kolloquien, Technische Textilien, Denkendorf, 2001.

[21] Hufenbach, W., Blazejewski, W., Kroll, L., Böhm, R., Gude, M. \& Czulak, A., Manufacture and multi-axial test of composite tube specimen with braided glass fibre reinforcement. Journal of Material Processing Technology, 162/163, pp. 65-70, 2005. doi: http://dx.doi.org/10.1016/ j.jmatprotec.2005.02.212

[22] Cherif, C., Diestel, O. \& Gries, T., Textile Halbzeuge und Halbzeugfertigung. Textile Verbundbauweisen und Fertigungstechnologien für Leichtbaustrukturen des Fahrzeug- und Maschinenbaus, ed. W. Hufenbach, SDV - Die Medien AG: Dresden, 2007.

[23] Hufenbach, W., Textile Verbundbauweisen und Fertigungstechnologien für Leichtbaustrukturen des Maschinen- und Fahrzeugbaus. SDV - Die Medien AG: Dresden, 2007.

[24] Gruhl, A., Hanke, ,U., Seliger, T. Hufenbach, W., Lepper, M. \& Renner, O., Mechanische Vorrichtung zur Realisierung einer Öffnung mit veränderlicher Öffnungsweite. Patent DE 10 2011006647.0 (date of publication: 01.04.2012). 
[25] Speck, O., Milwich, M., Harder, D. \& Speck, T., Vom biologischen Vorbild zum technischen Produkt: der "technische Pflanzenhalm". Museo, 22, pp. 96-103, 2005.

[26] Milwich, M., Speck, T., Speck, O., Stegmaier, T. \& Planck, H., Biomimetics and technical textiles: solving engineering problems with the help of nature's wisdom. American Journal of Botany, 93, pp. 1455-1465, 2006. doi: http://dx.doi.org/10.3732/ajb.93.10.1455

[27] Milwich, M., Planck, H., Speck, T. \& Speck, O., Der technische Pflanzenhalm: ein bionisches Schmaltextil. Melliand Textilberichte - Band- und Flechtindustrie, 44, pp. 34-38, 2007.

This is an extended, revised and updated version of the paper published in WIT Transactions on Ecology and the Environment, Vol 138, (C) 2010 WIT Press, www.witpress.com, ISSN 1743-3541 (on-line), doi:10.2495/DN100361. 